\title{
Depth measurement with the slit-lamp microscope
}

\author{
E S PERKINS
}

From the Department of Ophthalmology, University of Iowa Hospitals and Clinics, Iowa City, IA 52242, USA

SUMmARY The sagittal distance of ocular structures can be obtained with a slit-lamp microscope providing the movement of the slit-lamp can be measured. A simple device consisting of a pointer attached by a spring clip to the axle of a Haag-Streit 900 slit-lamp is described. The pointer rides over a scale which slides with the slit-lamp. Comparisons of anterior chamber depth and lens thickness showed a high correlation between this optical method and ultrasound measurements.

During studies on the influence of environmental and other factors concerned in the development of cataract it became clear that it was important to extend these studies to the earliest stages of cataract formation. One feature of many cataracts is a reduction in sagittal thickness of the lens, and such a measurement provides a more objective assessment than describing slit-lamp microscope appearances. The present study was undertaken to design a simple, rapid means of measuring lens thickness which could be used in population surveys.

The sagittal distance of structures within the eye can be measured by a variety of special instruments such as the Goldmann pachymeter' for the cornea and anterior chamber, Stenstrom's ${ }^{2}$ optical method, slit-lamp photography using the Scheimpflug principle $^{34}$ and ultrasonography. When such special instruments are not available, the movement of the viewing system of a slit-lamp microscope can be used to measure the apparent depth of structures by focusing first on the anterior surface of the structure and measuring the movement required to focus on the posterior surface. In older models of the slit-lamp this movement could be measured by means of an Ulbrich drum, but this is not possible with modern slit-lamps, in which the viewing and illumination system is controlled by a joy stock. Krannig ${ }^{5}$ described a method of measuring the movement of such instruments by marking a strip of paper in the two positions of focus and claimed an accuracy of $\pm 0 \cdot 3$ $\mathrm{mm}$. Magnification of the movement should enable greater accuracy, and a simple apparatus designed for the Haag-Streit 900 slit-lamp is described.

Correspondence to C S O'Brien Library, Department of Ophthalmology, University of Iowa, Iowa City, IA 52242, USA.

\section{Material and methods}

The Haag-Streit 900 is mounted on perforated roller bearings running on plates with indentations fitting the perforations. The bearings are $40 \mathrm{~mm}$ in diameter, so that for a rotation of $360^{\circ}$ the sagittal movement is $40 \times \pi=125.66 \mathrm{~mm}$ or $0.349 \mathrm{~mm} /$ degree of rotation. By fixing a pointer by a spring clip to the axle and using a protractor with a radius of $10 \mathrm{~cm}$ the angular movement can be measured to at least $0 \cdot 5^{\circ}$. The protractor is mounted on a piece of Plexiglass with a footplate and a cut-out to go over the axle, so that the protractor slides backwards and forwards with the slit-lamp. In practice it was found to be more convenient to use a millimeter scale glued to the edge of a $2.5 \mathrm{~mm}$ thick sheet of methyl methacrylate with a pointer riding over the scale (Figs. 1,2). With this arrangement $1 \mathrm{~mm}$ on the scale represented a $0.2 \mathrm{~mm}$ movement of the slit-lamp.

In use the patient is seated at the slit-lamp with the head resting firmly on the headrest. The slit-lamp is focused on the anterior surface of the cornea and the pointer brought back to zero by means of an adjustable stop. The slit-lamp is then advanced to focus on the anterior surface of the lens and the scale reading noted. This manoeuvre is repeated until consistent readings are obtained.

For measurement of the thickness of the lens the slit-lamp is focused on the anterior lens surface and the pointer zeroed. The slit-lamp is then moved to focus on the posterior lens surface and the reading noted.

With this apparatus it is possible to measure the apparent depth of the anterior chamber and apparent thickness of the lens to $\pm 0.2 \mathrm{~mm}$. Several measure- 


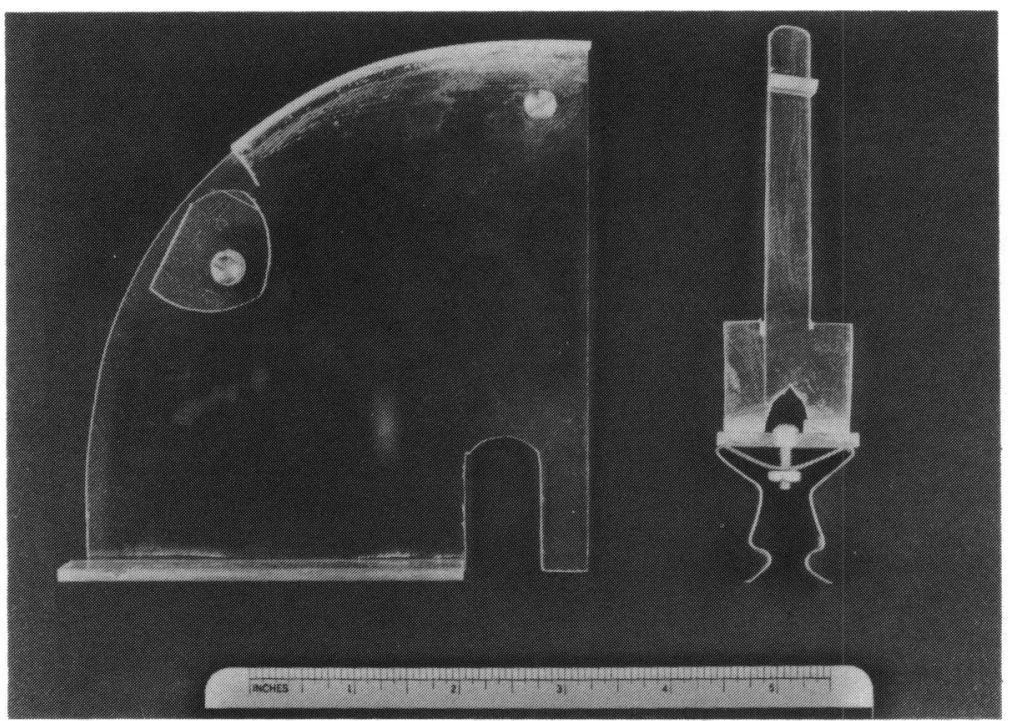

Fig. 1 Plexiglass plate with scale and cut-out for the axle of the slitlamp and the pointer with spring clip.

ments can be made quickly until a repeatable reading is obtained. If the angle between the slit and the microscope is small, the thickness of the lens can be measured through an undilated pupil.

The relationship between the true depth and the apparent depth of the anterior chamber can be calculated according to Linstedt ${ }^{6}$ from the equation:

$$
\text { True depth }=\frac{r \times n \times X}{r+(n-1) X}
$$

where $r$ = radius of curvature of the cornea, $\mathrm{n}=$ refractive index of aqueous, $\mathrm{X}=$ apparent depth.

The apparent depth of the anterior chamber was measured in 70 eyes and the lens thickness measured in 46 eyes with clear lenses. Ultrasonic biometry with a Storz Alpha 20/20 biometric ruler was also done on these eyes and the results were compared with the optical measurements.

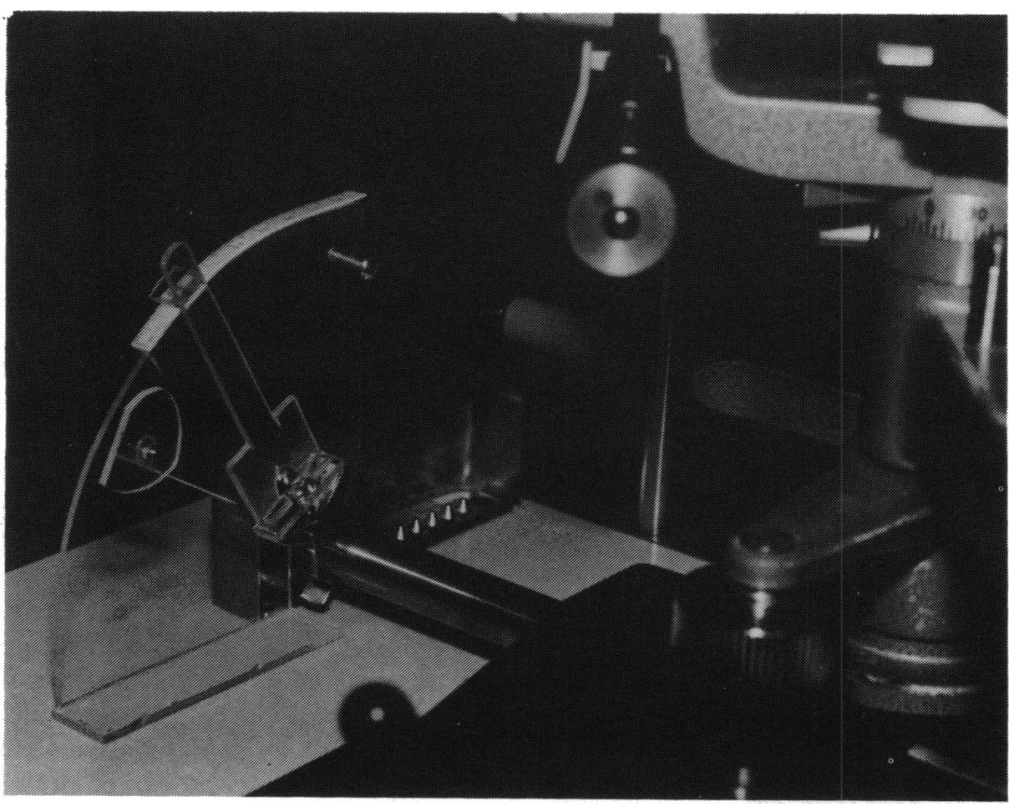

Fig. 2 The apparatus attached to the slit-lamp microscope. 
Results

\section{ANTERIOR CHAMBER DEPTH}

The slit-lamp measurements were corrected by means of Linstedt's formula assuming a mean anterior corneal radius of $7.8 \mathrm{~mm}$ and a refractive index of 1.34 for the aqueous. The mean difference between the optical and ultrasound measurements was $0 \cdot 16 \pm 0.3 \mathrm{~mm}$, the ultrasound measurements being higher by this amount. The mean anterior chamber depth by the optical method was 3.04 \pm 0.54 $\mathrm{mm}$ and the mean of the ultrasonic measurements was $3 \cdot 27 \pm 0 \cdot 41 \mathrm{~mm}$. This difference is statistically significant $(\mathrm{p}<0.01)$, but probably not clinically significant.

Linear regression analysis between the ultrasound and optical readings gave a correlation coefficient of $r=0.77$ with a slope of 0.84 and intercept of $0 \cdot 34$. The results for all right eyes are shown in Table 1.

CLEAR LENSES

A comparison of the ultrasound and apparent thick-

Table 1 Comparison of ultrasonic and optical measurements of anterior chamber depth

\begin{tabular}{|c|c|c|c|}
\hline Ultrasonic & Optical & Ultrasonic & Optical \\
\hline 3.9 & 3.55 & 3.3 & $2 \cdot 91$ \\
\hline $3 \cdot 8$ & $3 \cdot 34$ & 3.0 & $2 \cdot 69$ \\
\hline $3 \cdot 2$ & 3.55 & $2 \cdot 8$ & $2 \cdot 69$ \\
\hline 3.4 & $3 \cdot 13$ & $4 \cdot 1$ & 3.97 \\
\hline 3.9 & $4 \cdot 17$ & 3.5 & $3 \cdot 34$ \\
\hline $3 \cdot 7$ & $3 \cdot 13$ & $3 \cdot 5$ & 3.55 \\
\hline $3 \cdot 3$ & 3.02 & 3.8 & $3 \cdot 13$ \\
\hline $3 \cdot 0$ & 2.69 & $3 \cdot 6$ & $2 \cdot 91$ \\
\hline 3.5 & $3 \cdot 13$ & $2 \cdot 6$ & $2 \cdot 91$ \\
\hline 3.4 & 2.91 & $3 \cdot 3$ & $3 \cdot 34$ \\
\hline $2 \cdot 6$ & 2.46 & 3.5 & $3 \cdot 14$ \\
\hline $3 \cdot 8$ & $3 \cdot 34$ & $3 \cdot 1$ & $2 \cdot 69$ \\
\hline $3 \cdot 1$ & 3.34 & $3 \cdot 2$ & $2 \cdot 91$ \\
\hline $3 \cdot 1$ & $3 \cdot 34$ & 3.4 & $3 \cdot 34$ \\
\hline $3 \cdot 1$ & $2 \cdot 91$ & 3.4 & $3 \cdot 34$ \\
\hline $3 \cdot 6$ & $3 \cdot 13$ & $3 \cdot 0$ & 2.91 \\
\hline $3 \cdot 0$ & $3 \cdot 13$ & $2 \cdot 8$ & 2.46 \\
\hline $3 \cdot 0$ & $2 \cdot 91$ & $3 \cdot 2$ & $2 \cdot 91$ \\
\hline $4 \cdot 0$ & $4 \cdot 17$ & 3.4 & 3.55 \\
\hline $3 \cdot 6$ & $3 \cdot 13$ & $2 \cdot 8$ & $2 \cdot 46$ \\
\hline $3 \cdot 1$ & $3 \cdot 13$ & 3.5 & 3.55 \\
\hline 3.7 & $3 \cdot 34$ & $2 \cdot 4$ & $2 \cdot 24$ \\
\hline 3.8 & $3 \cdot 76$ & 3.0 & 2.69 \\
\hline 2.9 & $3 \cdot 13$ & $2 \cdot 8$ & 2.69 \\
\hline $2 \cdot 7$ & $2 \cdot 91$ & 3.4 & $2 \cdot 91$ \\
\hline $3 \cdot 1$ & $2 \cdot 69$ & $2 \cdot 6$ & $2 \cdot 91$ \\
\hline $3 \cdot 2$ & $2 \cdot 91$ & 3.9 & $3 \cdot 34$ \\
\hline $3 \cdot 8$ & 3.76 & $3 \cdot 1$ & $3 \cdot 51$ \\
\hline $3 \cdot 1$ & 2.91 & $3 \cdot 3$ & $2 \cdot 22$ \\
\hline $3 \cdot 2$ & $2 \cdot 91$ & $3 \cdot 2$ & $2 \cdot 66$ \\
\hline $3 \cdot 2$ & $3 \cdot 13$ & 3.0 & 2.44 \\
\hline 3.9 & $3 \cdot 34$ & 3.0 & 2.44 \\
\hline $3 \cdot 6$ & $4 \cdot 27$ & $2 \cdot 8$ & 2.44 \\
\hline 3.9 & 3.97 & 2.9 & 2.44 \\
\hline 2.9 & $2 \cdot 91$ & & \\
\hline
\end{tabular}

Table 2 Comparison of ultrasonic and optical measurements of lens thickness

\begin{tabular}{llll}
\hline Ultrasonic & Optical & Ultrasonic & Optical \\
\hline $4 \cdot 1$ & $5 \cdot 0$ & $4 \cdot 1$ & $4 \cdot 0$ \\
$4 \cdot 4$ & $4 \cdot 1$ & $4 \cdot 4$ & $4 \cdot 6$ \\
$3 \cdot 6$ & $3 \cdot 6$ & $3 \cdot 8$ & $4 \cdot 2$ \\
$4 \cdot 5$ & $4 \cdot 8$ & $3 \cdot 7$ & $3 \cdot 8$ \\
$3 \cdot 9$ & $4 \cdot 0$ & $4 \cdot 7$ & $4 \cdot 8$ \\
$4 \cdot 5$ & $4 \cdot 6$ & $4 \cdot 7$ & $4 \cdot 8$ \\
$4 \cdot 1$ & $4 \cdot 0$ & $4 \cdot 6$ & $4 \cdot 8$ \\
$4 \cdot 9$ & $5 \cdot 2$ & $4 \cdot 1$ & $4 \cdot 0$ \\
$4 \cdot 3$ & $4 \cdot 6$ & $4 \cdot 1$ & $4 \cdot 2$ \\
$4 \cdot 1$ & $4 \cdot 3$ & $3 \cdot 6$ & $3 \cdot 6$ \\
$4 \cdot 8$ & $5 \cdot 0$ & $3 \cdot 5$ & $3 \cdot 4$ \\
$3 \cdot 1$ & $3 \cdot 4$ & $4 \cdot 7$ & $5 \cdot 2$ \\
$4 \cdot 2$ & $4 \cdot 0$ & $4 \cdot 7$ & $5 \cdot 2$ \\
$4 \cdot 3$ & $4 \cdot 4$ & $4 \cdot 4$ & $4 \cdot 4$ \\
$4 \cdot 3$ & $5 \cdot 0$ & $4 \cdot 3$ & $4 \cdot 4$ \\
$4 \cdot 5$ & $4 \cdot 8$ & $3 \cdot 5$ & $3 \cdot 6$ \\
$4 \cdot 9$ & $4 \cdot 6$ & $4 \cdot 4$ & $4 \cdot 0$ \\
$4 \cdot 3$ & $4 \cdot 4$ & $4 \cdot 6$ & $4 \cdot 8$ \\
$3 \cdot 9$ & $4 \cdot 6$ & $4 \cdot 1$ & $4 \cdot 6$ \\
$4 \cdot 2$ & $4 \cdot 4$ & $4 \cdot 3$ & $4 \cdot 6$ \\
$4 \cdot 8$ & $5 \cdot 4$ & $4 \cdot 4$ & $4 \cdot 6$ \\
$4 \cdot 0$ & $4 \cdot 6$ & $4 \cdot 8$ & $4 \cdot 8$ \\
$4 \cdot 1$ & $4 \cdot 2$ & $4 \cdot 8$ & $5 \cdot 0$ \\
$5 \cdot 3$ & $5 \cdot 2$ & & \\
\hline & & & \\
\hline
\end{tabular}

ness of the lens by linear regression analysis gave a correlation coefficient of 0.86 with a slope of 0.99 and an intercept of $0 \cdot 25$, so that there were only small differences between the ultrasound measurements and the apparent thickness as measured with the slitlamp. The results for all right eyes are shown in Table 2.

\section{Discussion}

These results suggest that there is a good correlation between depth measurements obtained by measuring the movement of a slit-lamp microscope and those obtained by ultrasound. The agreement is not quite so good for anterior chamber depth as for lens thickness, possibly because individual corneal curvature measurements were not done and the calculations were based on a mean value of $7.8 \mathrm{~mm}$.

Krogsaa $e t$ al. ${ }^{7}$ calculated the ratio of the intraocular distance divided by the corresponding slitlamp movement for the anterior chamber, the lens, and the vitreous body. Their calculations were based on Gullstrand's emmetropic eye with a Goldmann fundus contact lens in place, so that the optical conditions were not the same as measurements made without a contact lens. They reported a ratio of 1.45 between the intraocular distance and the slit-lamp movement for the anterior chamber and a ratio of 1.64 for the lens. My measurements without a contact lens gave a ratio of 1.54 for the anterior chamber and 1.02 for the lens. The figure for the anterior chamber 
is fairly close to their calculated value, but the ratio for the lens is considerably less. It is certainly rather surprising that the apparent thickness of the lens as measured from the movement of the slit-lamp should be almost the same as the values obtained by ultrasonic biometry; this is presumably due to the smaller difference in refractive index between the aqueous and the lens and that of air and the aqueous. If a value of 0.963 (the difference between the refractive index of aqueous and refractive index of the lens) is used for $n$ in Linstedt's formula, the ratio between the intraocular distance and slit-lamp movement is 0.95 - much closer to the present results.

The primary purpose of this study was to see if a simple optical method of measuring lens thickness was sufficiently accurate for use in population surveys where more elaborate methods might not be feasible. The reported results suggest that measurement of slit-lamp movement compares well with ultrasonic biometry. The movement could be measured electronically with, for example, a potentiometer as was done by Krogsaa et al.,' but the method described here is simple to zero and gives a direct reading.

A similar apparatus to that described for the Haag-
Streit slit-lamp could also be devised for other slitlamps which employ roller bearings.

This research was supported in part by an unrestricted grant from Research to Prevent Blindness. Statistical analysis was done by Ms Shu-Jane Tan of the Department of Preventive Medicine, University of Iowa.

\section{References}

1 Goldman H. Ein neuer Messokular für die spaltlampe. Ber Dtsch Ophthalmol Ges 1932; 49: 435-7.

2 Stenstrom $S$. An apparatus for measuring the depth of the anterior chamber, based on Linstedt's principle. Acta Ophthalmol (Kbh) 1953; 31: 265-70.

3 Goldmann H. Eine Methode zur Volumbestimmung der Vorderkammer des lebenden Menschen. Ophthalmologica 1941; 102: 7-12.

4 Brown N. Slit-lamp photography. Trans Ophthalmol Soc UK 1969; 89: 397-408.

5 Krannig D. Vereinfachte Tiefenmessung, insbesondere am vor deren Augapfl. Ber Dtsch Ophthalmol Ges 1956; 60: 296-7.

6 Linstedt F. Über die Messung der Tiefe der vorderen Augenkammer mittels eines neun für klinischen Gebrauch bestimmen Instrument. Arch Augenheilkd 1916; 80: 104-67.

7 Krogssa B, Fledelius H, Larsen J, Lund-Andersen H. Photometric oculometry. 1. An analysis of the optical principles in slitlamp fluorophotometry. Acta Ophthalmol (Kbh) 1984; 62: 274-89.

Accepted for publication 5 March 1987. 